\title{
Effect of Pure and Binary Azeotropic Fluids on Heat Pipes Performance
}

\author{
Khalifa Bogarrasa ${ }^{a, *}$, Moussa Khlifa ${ }^{b}$ \\ a Department of Mechanical Engineering, Faculty of Technical Sciences, Sebha, Libya \\ ${ }^{b}$ Department of Chemistry, Faculty of Science, University of Sebha, Sebha, Libya
}

\section{A R T I C L E I N F O}

Received: 07 October 2019

Revised: 27 November 2019

Accepted: 09 December 2019

Available online: 19 December 2019

\section{K E Y W O R D S}

\section{Heat pipe}

Wick structure

Working fluids

Sintered Wicks

Azeotropic fluids

\section{A B S T R A C T}

Azeotropic fluids are considered to be a beneficial discovery used in various operations involving mechanical performance of machines. It is the thermodynamic property of the fluids to absorb heat and dissipate it. For instance, the addition of alcohols in water may increase the performance of these fluids. The objective of this work was to conduct a comparative study on heat pipe performance with different working fluids. The working fluids chosen for the study were water and pure ethanol. The concentrations of ethanol in water differed between $25 \%$ and $95 \%$. The material of heat pipes was copper with a sintered wicks structure. The experimental results revealed that, the evaporator temperature for water was lower than that of the ethanol and its mixture at high heating input. However, the heat transported by the heat pipes of water was considerably greater than that of the heat pipes of ethanol and binary fluids as working fluids.

\section{G R A P H I C A L A B S T RACT}

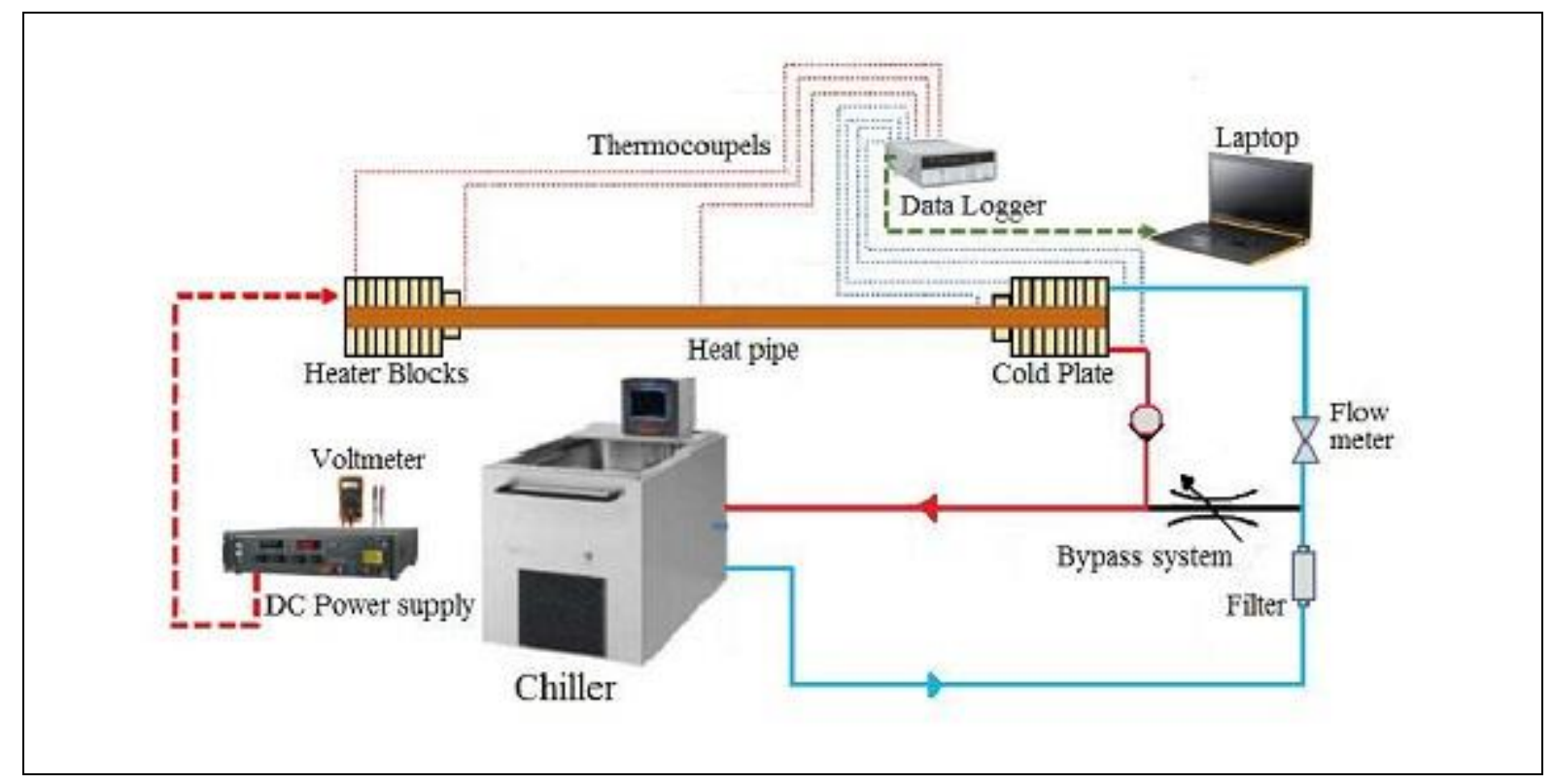

* Corresponding author's E-mail address: khlifa853000@gmail.com 


\section{Introduction}

As one of the two-phase heat transfer technology, a heat pipe is a device which transfers heat using both the phase transition and thermal conductivity [1]. Majority of heat pipes consist of a sealed tube comprised of a material which has a high thermal conductivity [2]. This material is used in hot environments as well as cold ones. It can consist of metals such as aluminium or copper. All the air is removed from the heat pipe by a vacuum pump. The pipe can then be filled with the working fluid which is sometimes known as a coolant. The type of working fluid used is determined by the operating temperature of the heat pipe. Many different types of working fluids are used such as mercury, sodium, acetone, alcohols, and water [2]. The lower pressure in the pipe causes the fluid to partially vaporize. This means, there will be both a fluid and a liquid phase within the pipe. The vacuum allows the working gas to be used directly rather than passing through another gas. This may improve the efficiency as the vapour passing to the cold end of the heat pipe moves with the speed of the molecules. This means that a heat pipe is a rapid method of heat transfer which is only limited by the speed with that the vapour takes to change to a liquid at the cold end of the pipe [2]. The schematic of a conventional heat pipe is shown in Figure 1.

\section{Heat pipe components}

\section{Container}

According to Groll et al. [4] , copper is the most common material used as a container in the heat pipes that work at low temperature. It provides great advantages. It is very compatible with water and other low temperature working fluids. In addition, it has larger thermal conductivity. In the same vein, for having low density and light weight, aluminium is utilized as a heat pipe. It is very compatible with ammonia which makes it the standard heat pipe for satellite thermal control. It also can be used to form a wide range of profiles with complex shapes by the process of extrusion. A statement is given by Reay and Kew [5] regarding the isolation of the working liquid as of the outside environment. They emphasized that it is a necessary that container should be leak proof as well as sustain the pressure degree of difference across its wall and it should have the ability to relocate into and away from the working liquid. Copper, aluminium and stainless steel are the most commonly used container materials as stated by Reay and Kew [5]. Copper can work perfectly in the temperature of $0{ }^{\circ} \mathrm{C}$ and $200{ }^{\circ} \mathrm{C}$ and therefore, it is preferred for electronics cooling applications.

\section{Sintered wicks}

A detailed analysis of sintered copper wicks applied in heat pipes is carried out by Leong, Liu and Lu [6]. They stated that a major benefit of sintered copper wicks to be the existence of lesser pores when compared to wire mesh and the better controllability of pore size and porosity to improve the heat pipe performance. They compared a constant sphere size copper powder when sintered at different temperatures and durations in the sinter oven while doing their experiment. They fund that sintering temperature, whether it is $800{ }^{\circ} \mathrm{C}$ or $1000{ }^{\circ} \mathrm{C}$ has less of an impact on the whole porosity of the wick in comparison to sintering time which when extended can lower the porosity quite significantly. The pore size distribution in the wick is greatly influenced by the sintering temperature. There are significant numbers of pores below the size of $0.35 \mu \mathrm{m}$ when the temperature is below $800{ }^{\circ} \mathrm{C}$. But at higher temperature, this is not visible. The high performance sintered heat pipes to be between 50 and $100 \mathrm{~W} / \mathrm{cm}^{2}$ as they confirmed finally. 
Authors in [7] undertook another interesting approach in order to raise the achievable heat flux in a sintered wick. He gave importance on the use of bi-porous wicks in order to remove high heat fluxes. They manage to achieve heat fluxes up to 494 $\mathrm{W} / \mathrm{cm}^{2}$, which is almost 2.5 times what is believed to be the critical heat flux limit for sintered heat pipes with their wick, which consists of clusters of sintered material of finer pores within the cluster.

The above stated approach is similar to the approach of [8], but points into a different direction, rather than changing the structure of the wick, in their approach the shape of the wick has been changed and extensive research on the optimum shape of the wick has been conducted. They are mimicking the shape of a grooved heat pipe through a sintered structure within a plain tube which forms the grooves. It provides extra capillary forces through the stacks which form the grooves for the working liquid to come back to the evaporator and still have low resistance against vaporisation in the evaporation section which is the advantage of this approach. They used titanium as material whilst the other papers presented used copper powder for their wick. Also copper powder has been used as part on their composite wicks in the approach presented in $[9,10]$ (Figure 2).

\section{Working fluids (Fluid mixture)}

When two or more liquids are mixed together to form a new compound which cannot be broken down by simple distillation, the resulting liquid is known as an azeotrope. This peculiar characteristic of the new chemical outcome is due to the vapour having the same ratio of constituents that are present in the original mixture. Azeotropes were previously referred to as constant boiling mixtures. There is a wide variety of azeotropic mixtures. Each one of these mixtures has its own particular characteristics [11].

Figure 1. Schematic and operation of heat pipe [3]

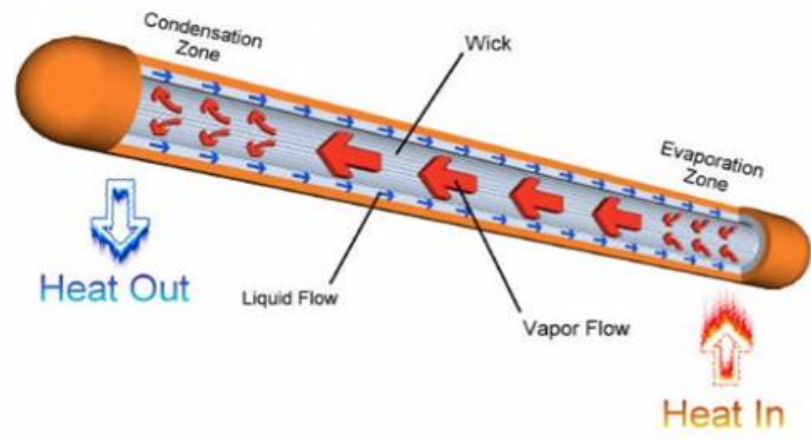

Figure 2. View into Sintered heat pipe [10]

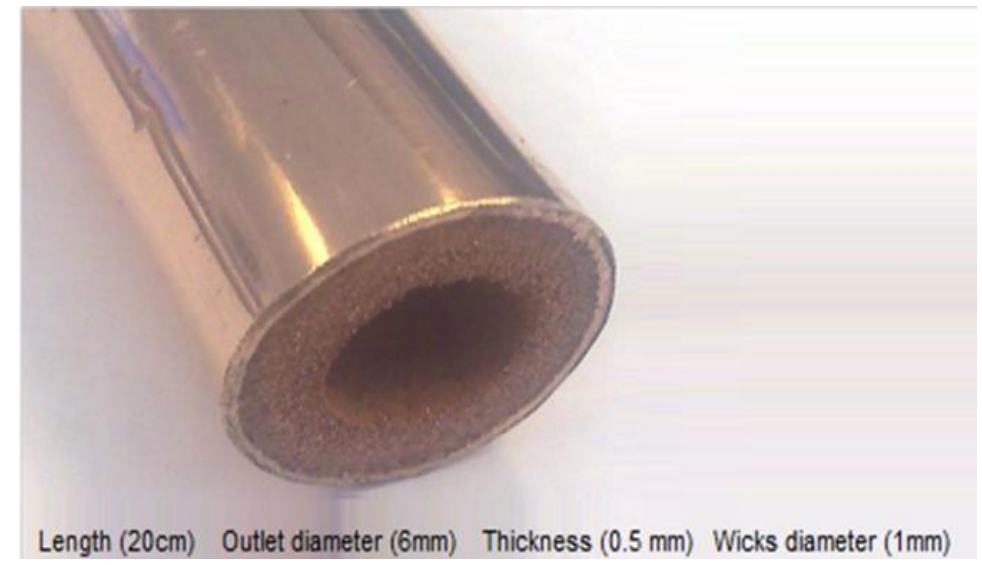


An important distinction among azeotropes, which is particularly important with regard to heat pipes, is the boiling point of the mixture. An azeotrope can have a boiling point which is less than that of its constituents in which case it is considered a positive azeotrope [12]. If the boiling point is lower than its constituents what it is said to be a negative azeotrope. The positive azeotrope is also known as the pressure maximum azeotropes or minimum boiling mixture. On the contrary, the negative azeotropes are known as pressure minimum or maximum boiling mixtures. Azeotropes can be comprised of only two constituents that are known as binary azeotropes. The azeotropes which have three constituents are known as tertiary azeotropes [11].

There are critical matters which must be considered when choosing the best performing working fluid for a heat pipe [13]. These factors are important for azeotrope as well. One of these factors is the surface tension. This is a force which acts in word and perpendicular to the boundary of a surface. Any heat pipe generally decreases the interface area. This results in the working liquid having a shape which uses the minimum amount of an area. If the pipe consists of a vacuum inside it, then in zero gravity the liquid will be a perfect sphere [5].

The surface tension is the result of repulsive and attractive forces on the molecules near the interface area. Thermodynamically, the surface tension results from energy being stored in the molecules which are near the interface. This energy is in the form of hydrogen or metallic bonding, as well as dispersion forces. This tension in a liquid which is non polar is caused only by the dispersion forces. However, in liquids which are hydrogen bonded the dispersion forces and the hydrogen bonding contribute to the higher level of surface tension [14]. There are especially high surface tensions in liquid metals, such as mercury, due to the dispersion forces being combined with a metallic force. This means the surface tension of a liquid metal is considerably higher than a liquid which is hydrogen bonded such as water. The surface tension also varies by temperature. When the temperature is increased, the surface tension will decrease. In the case of water, there is a nearly linear relationship between the temperature and surface tension [12].

Another important factor which must be taken into consideration is the boiling limit of the working liquid [12]. In any heat pipe, the boiling occurs in the wick near the evaporating wall. There is a thin film of evaporation present at the interface between the solid, liquid, and vapour. This area decreases quickly since the boiling condition will dominate the phase change within the system. The vapour which forms near the base of the wick prevents the working fluid from re-entering the system. The conductivity of the paper is lower than the fluid [5]. Therefore, the conductivity of the wick significantly decreases when this reaction occurs. Heat transferring due to boiling in the wick must be avoided since it can lead to the heat pipe drying out [14].

Another important factor to consider when choosing a working fluid is the entrainment limit [5]. When the liquid and vapour are flowing in opposite directions, there is a frictional shear stress that is presented at the vapour-liquid interface. This can slow down the flow of liquid, which is returning to the evaporator. This causes the velocity of the vapour to increase. There is also an increase of the paper flow near the liquid-vapour interface [15]. This reaction is dependent upon the surface tension. It is also dependent upon the viscosity of the liquid as well as the density of both the liquid and vapour phase. If the influence of the frictional shear upon the vapour-liquid interface is too large, the liquid will not return properly to the evaporator. 
Table 1. Azeotropes of water from lide [12]

\begin{tabular}{cc} 
Specifications & 78.4 \\
Boiling point of chemical ${ }^{\circ} \mathrm{C}$ & 78.1 \\
Boiling point of water/chemical azeotrope ${ }^{\circ} \mathrm{C}$ & -114.2 \\
Freezing point of chemical ${ }^{\circ} \mathrm{C}$ & $95.5 \%$ \\
\hline Percent of chemical in azeotrope & \\
\hline
\end{tabular}

This causes the evaporator to dry out. When this occurs, the heat pipe reaches a heat transport limit. This is also known as the entrainment limit [5]. This paper will be concerned primarily with ethanol of water since this compound generally has excellent thermodynamic properties [12]. Table 1 below lists a number of properties for that compound.

\section{Properties of a fluid mixture}

The fluid solution contains water and ethylene glycol. To calculate the quantities of bound water in the solution, the weight of the freezing water is subtracted from the total weight of the mixture. This is represented by the following equation [16].

$$
W_{b}=W_{t}-W_{f}
$$

Where $W_{b}$ is the bound water, $W_{t}$ is the total water, and $W_{f}$ is the freezable water. The ratio of $W_{b} / W_{t}$ represents the bound water to total water in the fluid. This ratio also helps to calculate the molality of the solution, as the two values have an inversely proportional relationship. For instance, of ethylene glycol solution increases from 16 per cent to 42 per cent as the value for molality is increased from one mol/ $\mathrm{kg}$ to five $m o l / k g$. The ratio of the $W_{b} / W_{t}$ also defines the ability water bonding with hydrogen along with the freezing point of the fluid solution. The high ratio of $W_{b} / W_{t}$ would result is a lower freezing point [17].

Another ratio, $N_{b} / N_{s}$, which represents the quantity of bound water by unit $\mathrm{mMol}$ of the solution. This too, has an inversely proportional relationship with the molality.
For instance, if the $N_{b} / N_{s}$ for ethylene decreases from 9.0 to 4.6 , then the molality would rise from one $\mathrm{mol} / \mathrm{kg}$ to five $\mathrm{mol} / \mathrm{kg}$. The reason for this relationship is that the probability of hydrogen bond formation between the solvent increases as the molality increases [17]. According to Chapoy et al. [18], the vapor pressure of the fluid is dependent on the volatility of the solution. In the first case, if the solution is volatile, then the individual vapor pressure of the solvents would have a contributing influence on the overall vapor pressure of the fluid. However, for nonvolatile solutions, the vapor pressure in fluid would not be too significant. For calculations, the equation for Raoult" law can be used to determine the vapor pressure of the overall fluid if the mole fraction is known. The equation for Raoult is:

$$
P_{\text {solvent }}=X_{\text {solvent }} \times P_{\text {solvent }}^{o}
$$

Where $\mathrm{X}$ and P represents the two solvents. The solubility of water and ethylene glycol can be calculated by using the following two equations [19].

$$
\begin{array}{lr}
\text { Water: } & k_{i j}=A+\frac{B}{T} \\
\text { Ethylene glycol: } & A+B \times T
\end{array}
$$

For the above equations, 'A' and 'B' are two constants, and ' $\mathrm{T}$ ' is the value of temperature in Kelvin. Next, the methods of obtaining the values for the latent heat of fusion of ice (solution) will be discussed. For more understanding, the latent heat of fusion for the mixture of water and ethylene glycol would be compared with other water-alcohol mixtures. 
Table 2. Specifications of heat pipe

\begin{tabular}{|c|c|}
\hline Specifications & Dimensions \\
\hline Radius in the condensing section (m) & $3.17 \times 10-5$ \\
\hline Outlet diameter $(\mathrm{mm})$ & 6 \\
\hline Thickness of the heat pipe (mm) & 0.5 \\
\hline Inlet diameter or vapour diameter $(\mathrm{mm})$ & 3 \\
\hline Characteristic dimension of the liquid-vapour (mm) & 0.036 \\
\hline Wick porosity (dimensionless) & 0.52 \\
\hline Sintered wicks diameter (mm) & 1 \\
\hline Length of heat pipe section $(\mathrm{cm})$ & 20 \\
\hline Effective length $(\mathrm{cm})$ & 14 \\
\hline Wick cross-sectional area $\left(\mathrm{m}^{2}\right)$ & $1.2087 \times 10^{-5}$ \\
\hline Wick permeability $\left(\mathrm{m}^{2}\right)$ & $1.43 \times 10^{-11}$ \\
\hline
\end{tabular}

Finally, to calculate the heat-transfer coefficients, the physical properties of water would be considered for this calculation as the concentration of the ethylene glycol is very small. From experiments, it has been observed that the average thermal resistance of the solution is $0.00165 \mathrm{~m}$ squared, this corresponds to the air gap value of 0.06 [20].

\section{Experimental}

\section{Experimental methodology}

The experiments were limited to the copper Sintered Wicks heat pipes with deferent concentrations of ethanol/water as working fluid. The specifications data for the heat pipe are presented in Table 2.

\section{Venting and filling techniques}

Venting and filling (as shown in Figure 3) was the process of entering the working fluid into the copper tube under negative pressure which is about $1.333 \times 10^{-7}$ bar for preparing the copper tube to perform as a heat pipe. This process was essential for the test of a heat pipe. It is a sensitive stage because any mistake while executing may cause the failure of the entire experiment. In this process, the metal pipe was filled with the correct amount of working fluid. Subsequently, the pipe was inserted to a venting rig to heat the pipe which was already filled with liquid at a controlled temperature. The temperature was adjusted at $100-200{ }^{\circ} \mathrm{C}$, and water was used as working fluid. This technique was used in our experiment as it has the provision of removing NCG's (non- condensable gases) out of the heat pipe. The temperature of the working fluid was kept higher than the venting rig to maintain variation in the pressure. The pressure begins to rise during the evaporation of water. This gradient of pressure helped to remove the NCG's by the pressure of water vapours if created, at the beginning of the vaporization. The final point of experiment was described by Engelhard [10]. This amount of working fluid on the outside of the top end of the pipe has reached its boiling temperature, it starts to evaporate and the person processing the pipe knows that the correct venting temperature has been achieved and NCG's are ready to be forced out of the pipe. Table 3 provides the statistics of weight gained by the filling the heat pipe.

\section{Experimental setup}

The details of the experimental setup are shown in the Figures 4 and 5 [21]. The rig can be tilted for $0^{\circ}$, and $90^{\circ}$. A computer was connected to a data logger. A power of $10 \mathrm{~W}$ was supplied to the heat pipes. When the fluid inside the tube was vaporized completely, the power was switched off and the apparatus allowed cooling down. 
Figure 3. Process of venting and filling of heat pipe

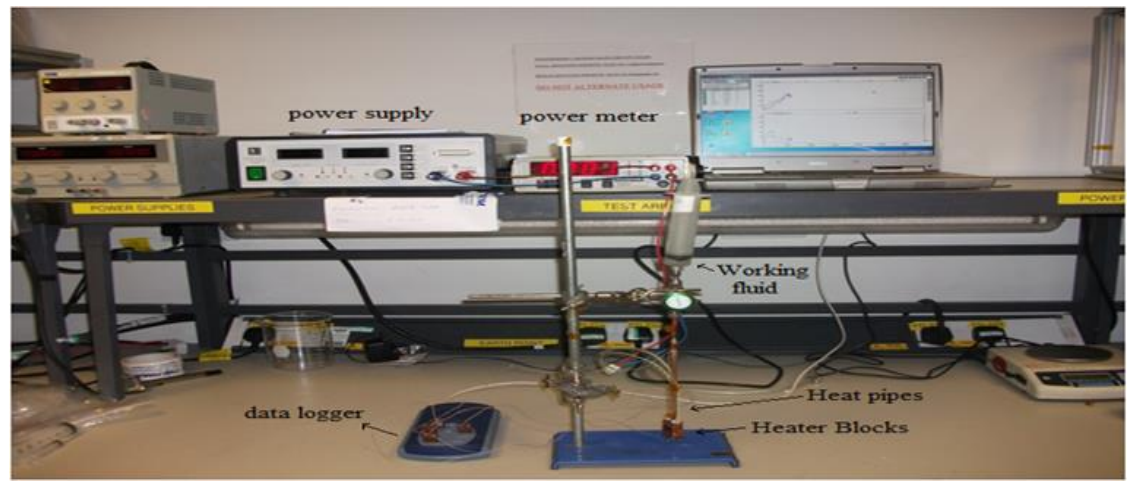

Table 3. Weight of experimental fluids in the heat pipe

\begin{tabular}{ccccc}
$\begin{array}{c}\text { Type } \\
\text { Wick material } \\
\text { Working fluid }\end{array}$ & $\begin{array}{c}\text { Heat pipe } 1 \\
\text { Sintered } \\
\text { Water }\end{array}$ & $\begin{array}{c}\text { Heat pipe } 2 \\
\text { Sintered } \\
\text { Ethanol }\end{array}$ & $\begin{array}{c}\text { Heat pipe 3 } \\
\text { Sintered } \\
95 \%\end{array}$ & $\begin{array}{c}\text { Heat pipe } 4 \\
\text { Sintered } \\
25 \%\end{array}$ \\
$\begin{array}{c}\text { Wight of empty heat } \\
\text { pipe }\end{array}$ & $27.65 \mathrm{~g}$ & $30.02 \mathrm{~g}$ & $27.949 \mathrm{~g}$ & $\begin{array}{c}27.54 \mathrm{~g} \\
\text { ethanol/water }\end{array}$ \\
$\begin{array}{c}\text { Wight of heat pipe after } \\
\text { filling }\end{array}$ & $29.16 \mathrm{~g}$ & $31.2 \mathrm{~g}$ & $29.66 \mathrm{~g}$ & $29.20 \mathrm{~g}$ \\
$\Delta \mathrm{w}(\mathrm{g})$ & 1.51 & 1.18 & 1.72 & 1.66 \\
\hline
\end{tabular}

Once the apparatus was cooled, it is switched on once again for $1 \mathrm{~h}$. The temperature is monitored carefully during the test. The apparatus was connected to a number of DC supplies to heat the pipes evenly. The cold plates dissipated the heat of the central processing unit. The coolant was a system of recirculation fluid flow chilling system that was combined by a flow meter as well as a bypass system to route the excess fluid. This assembly was utilized to control the drop at the pressure of the system and to monitor the chilling. Two thermocouples, one fixed at the inlet stream and the other at the outlet stream. These thermocouples ensured the accurate reading of energy transferring and to record any collapse in the heat system that may occur during the experiment. The USB data logger was attached to the computer and the testing rig that plotted the fluctuation in the parameter on to the computer screen. The power inputs can be noted from the digital display of power meters. The power rates can also be fed into the computer using serial cables. $T$ - Type thermocouples were used to measure the variation in temperature of the working fluids. The electromagnetic flow meter determined the pressure drop caused by any decrease in temperature. The bypass switch prevented the steam from entering into the system, preventing the reciprocating chillier from working under the heterogeneous pressures of the system, enabled it to work efficiently. Engelhard [10] reported that, the achievable flow rate of the given system was determined by the pressure drop through the cold plates. The flow through the cold plates can be controlled in a very accurate manner through a needle valve directly.

\section{Results and discussion}

In this study, the working fluids were water, ethanol, and two different concentrations of ethanol in water $25 \%$ and 95\%). Figure 6 demonstrates the vertical heat pipe with sintered wicks and water as working fluid. 
Figure 4. Test rig and instrumentation used for the thermal testing

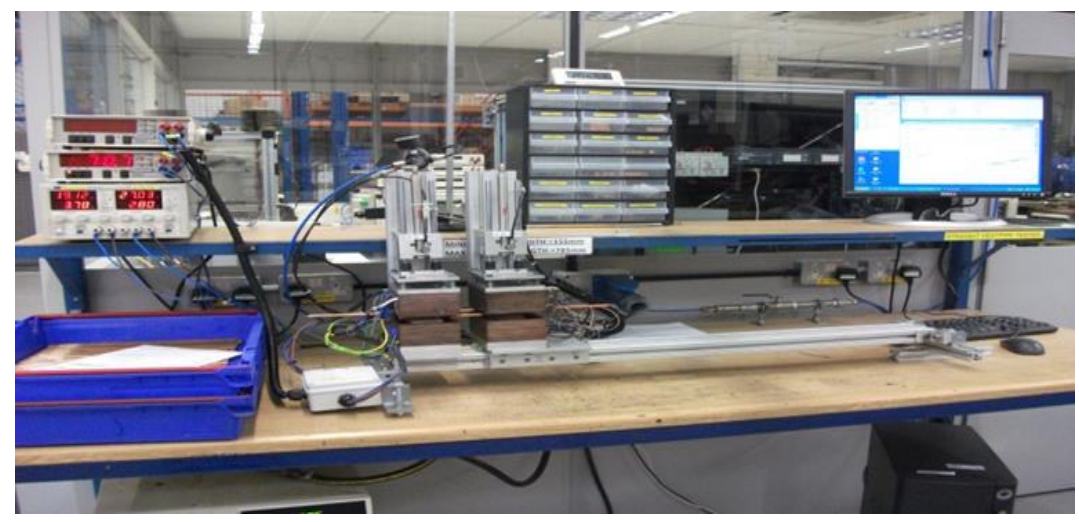

Figure 5. Schematic diagram of the test rig

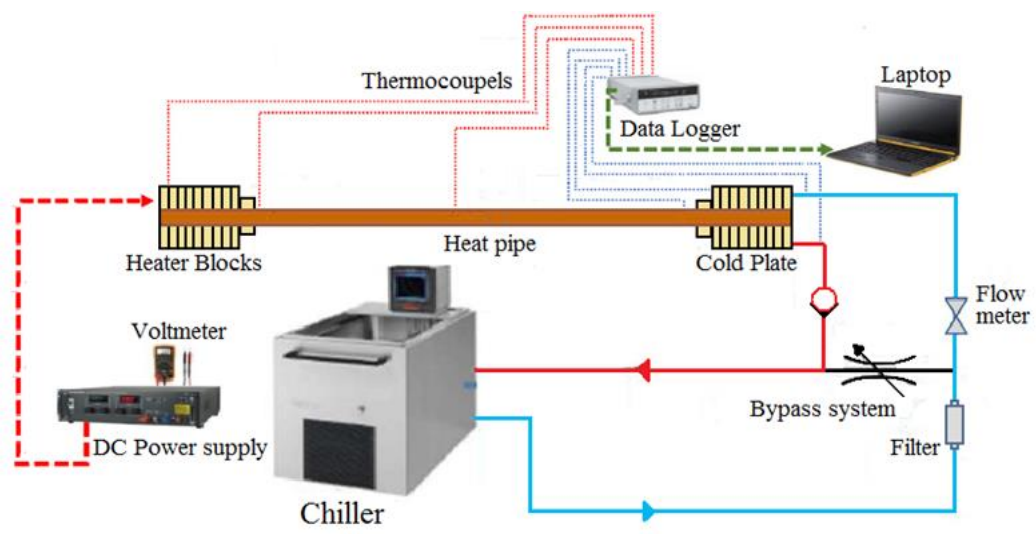

The axial temperature drop (Dt) from the condenser to end of the heat pipe evaporator was less than $2{ }^{\circ} \mathrm{C}$ for the all measurements. In most cases it was $\sim 1 \stackrel{\circ}{\circ}$. This clearly indicated that, the heat pipe was quite satisfactory. The temperature was almost constant, reflecting the operating thermal resistance in the vertical arrangement. The heat pipe continued to perform well beyond an operational temperature of $140^{\circ} \mathrm{C}$. The horizontal position revealed a slightly lower power (85 W) at the same temperature $\left(140^{\circ} \mathrm{C}\right)$ compared with that of the vertical angle of similar condition (Figure 7). However, the difference is diminutive and may be due to the gravity force that drags the working fluid and it settles down in the bottom of the container. It can be observed that the position of heat pipe may impact the performance. These results confirmed those obtained by Nemec P. et al. [3].

In case of pure ethanol and ethanol/water mixture (95 wt.\%) as working fluids, the measurements of thermal performance of heat pipe with vertical angle are shown in Figure 810. Power input increased gradually and the temperature of heat source was $120^{\circ} \mathrm{C}$. It can be noted that, the clear evaporator temperature for pure ethanol and azeotrope mixture of ethanol (95.5\% wt.) was higher compared with that of the water. The evaporator temperature for the pure ethanol and azeotrope mixture of ethanol (95.5 wt.\%) was about the same at all the heat inputs. Furthermore, the condenser temperature was relatively equal for the pure ethanol, water/ethanol, and water at the heat input ranging from $10 \mathrm{~W}$ to $30 \mathrm{~W}$. After $30 \mathrm{~W}$, the condenser temperature for water was lower than the pure ethanol and azeotrope mixture. The temperature of evaporator and condenser was about equivalent for pure ethanol and azeotrope mixture. On the contrast, the temperature was greater compared with that of the pure water. Therefore more thermal resistance was appeared. This clearly indicated that the heat pipe was functioning quite satisfactorily in that limits. 
Figure 6. Measured data of heat pipe with water as working fluid operating at angle $90^{\circ}$

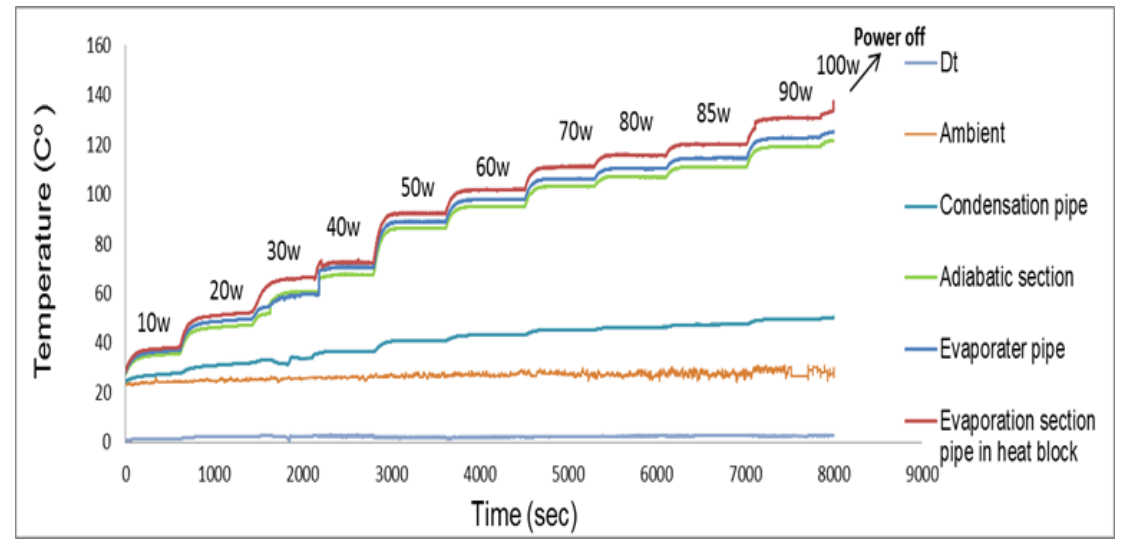

Figure 7. Measured data of heat pipe with water as working fluid operating at angle $0^{\circ}$

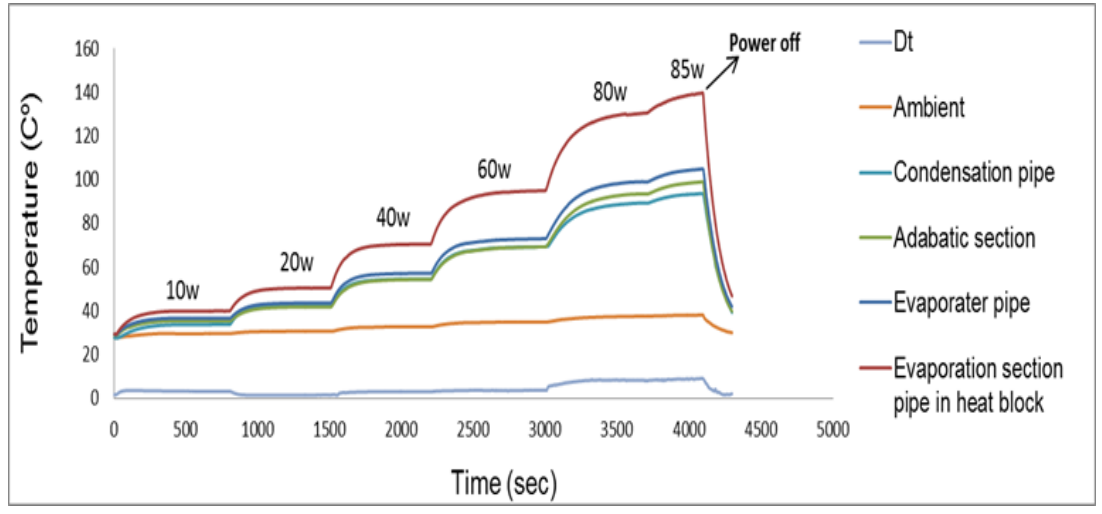

Heat pipe is being operated on maximum performance and maximum mass flow transfer in this position Patrik et al. [22]. Also reported that, the ideal working position of the heat pipe was at vertical position.

The heat pipe was satisfactory to $40 \mathrm{~W}$ heat input in the vertical position with temperature gain of fluid up to $120^{\circ} \mathrm{C}$. On the other hand, the heat pipe which tested in the horizontal arrangement as shown in Figure 9, the fluid started drying out at $10 \mathrm{~W}$ and when the power supply reaches a $20 \mathrm{~W}$, the test was stopped. In addition, the temperature of adiabatic cooling section was much higher than that of the condensation section. This caused a huge and rapid increase in the pressure, which increased the temperature variation (Dt). The present results could be attributed to the capillary pressure and surface tension of the ethanol.

In Figure 11, water-ethanol mixture (25 wt.\%) provided a better thermal performance than pure ethanol and the mixture of $(95 \%$ wt) as working fluids of same constituent. It is also obvious that from $10 \mathrm{~W}$ to $20 \mathrm{~W}$, the axial temperature drop was almost constant for 20 $\mathrm{W}$ and started increasing at $30 \mathrm{~W}$ heat input. While, from 30 to $45 \mathrm{~W}$ heat inputs, all fluids behaved similarly in heating zone. The reason behind that may be the difference of properties between ethanol and water as the boiling points and the latent heat of ethanol were less than water. Thus, water can boil hardly in low power inputs. As seen in Figure 11 , water-ethanol mixture (25 wt.\%) revealed a better thermal performance in comparison with that of the pure water as working fluid of heat pipes in low power input from $10 \mathrm{~W}$ to 30 $W$. As a result, it can transfer a big amount of heat at the levels of lower power input. However, the situation is reverse at high power input. These results confirmed those obtained by Pramod et al. [23].

In general, the trends of thermal resistance for all the mixing working fluids were approximately same in nature, as the difference in thermophysical values was minimal. As expected, the overall thermal resistance was increased. The substantial rise 
in thermal resistance in horizontal conditions was due to the partial dry out that started at some locations in the heat pipe. Among all the working fluids, the azeotrope mixture had a higher thermal resistance compared with that of the pure water. Therefore, it can be concluded that, the thermal resistance of azeotrope reduced by increasing the

Figure 8. Measured data of heat pipe with ethanol as working fluid operating at angle $90^{\circ}$

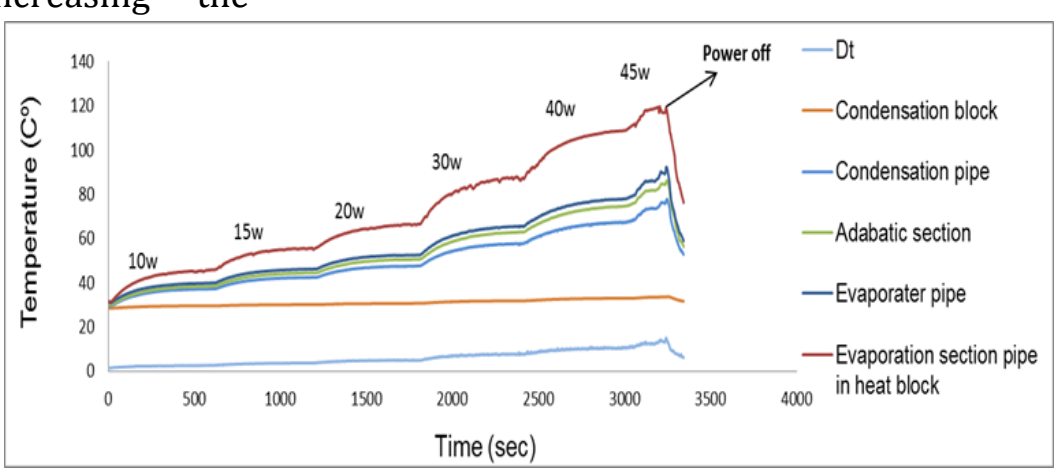

Figure 9. Measured data of heat pipe with ethanol as working fluid operating at angle $0^{\circ}$

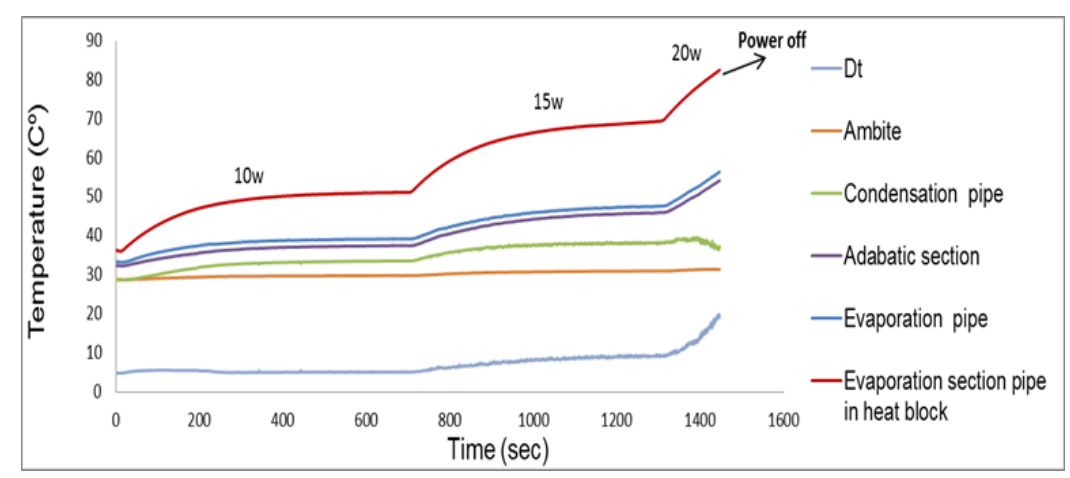

Figure 10. Measured data of heat pipe with $(95 \%)$ of ethanol as working fluid operating at angle $90^{\circ}$

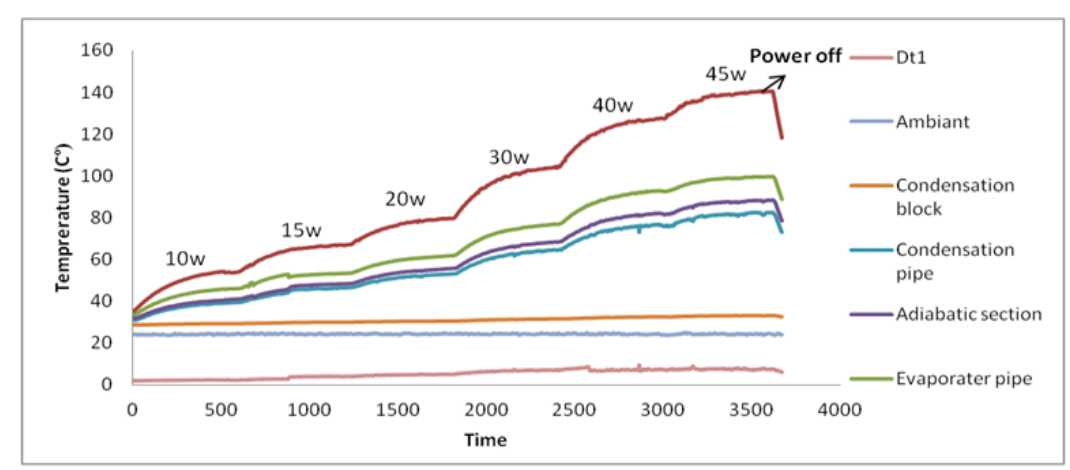

Figure 11. Measured data of heat pipe with $(25 \%)$ of ethanol as working fluid operating at angle $90^{\circ}$

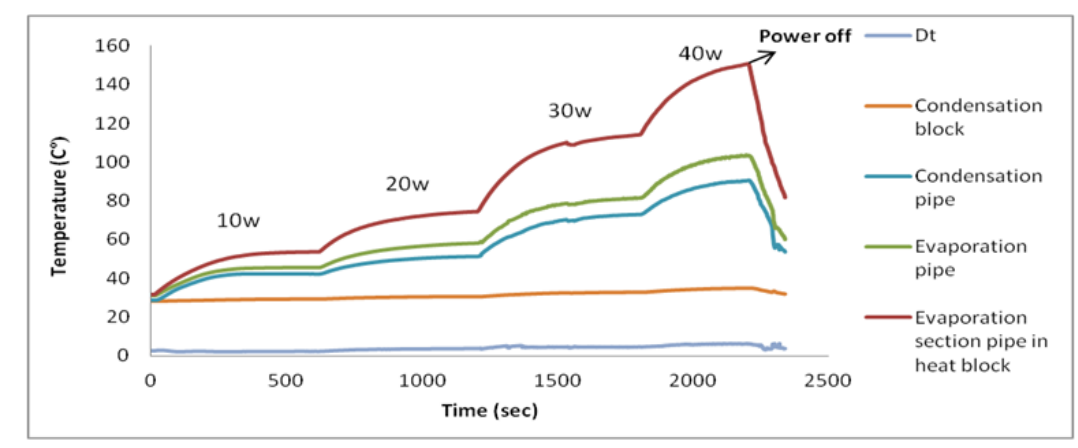
the concentration of water in ethanol also improved the evaporator heat transfer, allowed the interfacial surface tension gradients to enhance the flow and to improve the performance of the gravity-assisted heat pipe. 
Figure 12. Performance of copper water, Ethanol and the mixture as working fluids at angle $90^{\circ}$

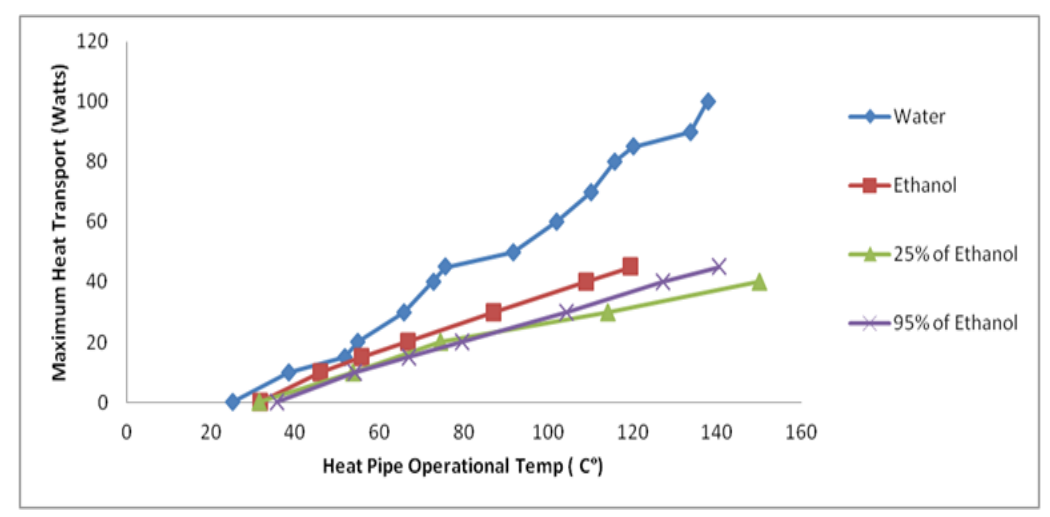

A comparison between the performances of water/ethanol and it's mixtures in heat pipe at vertical position is demonstrated in Figure 12. At lower heat input ( $45 \mathrm{~W})$, the level of temperature in mixture of ethanol and the pure of ethanol up to $140{ }^{\circ} \mathrm{C}$ was higher than that of the water temperature at the same heat input. This was attributed to the difference in boiling point and the dew point of the ethanol. Furthermore, the contact angle of the water to metallic surface was greater than the ethanol. In this way, heat pipe with water as working fluid at a vertical position may be regarded as an efficient. Water showed maximum value of heat transfer with lower thermal resistance. However, ethanol and the mixtures could reach a high temperature at low power levels.

\section{Conclusion}

In this study, a careful experimental of working fluids was made with different angles of the heat pipe such as, $0^{\circ}$, and $90^{\circ}$. The following conclusions were drawn from the study.

- The experimental test have shown water as a standard working fluid in both positions (vertical and horizontal), where all the parameters appear very smoothly.

- Ideal working position of ethanol heat pipe was vertical position.

- Ethanol can reach a high temperature at low power levels.

- No measurable difference was recorded between the pure ethanol and ethanol/water mixture (95\%) working fluids, in terms of overall thermal resistance.

- The boiling point of an azeotrope was less than that of its constituents which made it a positive working fluid for heat pipes.

\section{Acknowledgement}

The authors would like to appreciate the Faculty of Technical Sciences (Sebha) and the University of Sebha, Libya for their consist support and encouragement.

\section{Disclosure statement}

No potential conflict of interest was reported by the authors.

\section{References}

[1] A.A. Ahmed, P. Wang, G. Huang and C. Li, Int. J. Heat. Mass. Tran., 2019, 133, 474486.

[2] M.M. Rathore, R. Kapuno, Engineering heat transfer, Jones and Bartlett Publishers: London, 2011.

[3] P. Nemec, A. Cajar, M. Malcho, Global J. Technol. Optimizat., 2011, 3, 109-110.

[4] M. Groll, M. Schneider, V. Sartre, M.C. Zaghdoudi, M. Lallemand, Rev. Gen. Therm., 1998, 37, 323-352.

[5] D. Reay, P. Kew, Heat pipes, ButterworthHeinemann: UK, 2006.

[6] K.C. Leong, C.Y. Liu, G.Q. Lu, J. Porous Mater., 1997, 4, 303-308. 
[7] T. Semenic, Y.Y. Lin, I. Catton, D.B. Sarraf, Appl. Therm. Eng., 2008, 28, 278-283.

[8] G. Hwang, M. Kaviany, W. Anderson, J. Zuo, Int. J. Heat Mass Trans., 2007, 50, 14201434.

[9] M. Mwaba, X. Huang, J. Gu, Int. J. Energy Res., 2006, 30, 489-499.

[10] A. Engelhard, Issues in screen mesh heat pipe manufacturing and operation. Ph.D thesis, The University of Nottingham, Nottingham, 2010.

[11] J.G. Speight, N.A. Lange, Lange's handbook of chemistry, McGraw-Hill: New York, 2005.

[12] D.R. Lide, CRC handbook of chemistry and physics, CRC Press/Taylor and Francis Group: Boca Raton, Florida, 2009.

[13] M. Kutz, Mechanical engineers handbook, Wiley: New Jersey, 2006.

[14] H. Smirnov, Transport phenomena in capillary-porous structures and heat pipes, CRC Press/ Taylor and Francis Group: Florida, 2010.

[15] A. Bejan, A. Kraus, Heat transfer handbook. Wiley: New Jersey, 2003.
[16] M. Kuramae, Heat transfer characteristics of water heat pipe in conjunction with freezing or melting of working fluid, in: Proc. of 8th Int. Heat Pipe. Conf. Beijing, China, 1992, 244-249.

[17] G.M. Kontogeorgis, I.V. Yakoumis, H. Meijer, E. Hendriks, T. Moorwood, Fluid Phase Equilibria, 1999, 158, 201-209.

[18] A. Chapoy, B. Tohidi, Hooman Haghighi, J. Chem.Therm., 2008, 40, 1030-1037.

[19] I. Mellan, Industrial Solvents Handbook, Noyes Publishing: New Jersey, 1977.

[20] D.J. Goss, R.H. Petrucci, General Chemistry Principles \& Modern Applications, Petrucci, Harwood, Herring, Madura: Study Guide. Pearson/Prentice Hall, 2007.

[21] K. Bogarrasa, M. Khlifa, J. Pure. Appl. Sci., 2017, 16, 59-65.

[22] P. Nemec, Testing Thermal Properties of the Cooling Device with Heat Pipes, EPJ Web Conferences, proc. of 7th Int. Conf. on Experimental Fluid Mechanics, 2013, 45, 2-4.

[23] Pramod R. Pachghare, Ashish M. Mahalle, Procedia Eng., 2013, 51, 624-629.

How to cite this manuscript: Khalifa Bogarrasa*, Moussa Khlifa, Effect of Pure and Binary Azeotropic Fluids on Heat Pipes Performance, Adv. J. Chem. A, 2020, 3(4), 442-453. 